\title{
Effect of mirror therapy on hand functions in Egyptian chronic stroke patients
}

\author{
Hussein Shaker ${ }^{1}$, Ebtesam Mohammed Fahmy², Ayman Anwar Nassif Honin ${ }^{1}$ and Shaimaa Shaheen Mohamed ${ }^{2^{*}}$ (D)
}

\begin{abstract}
Background: Most stroke survivors (more than 60\%) suffer from persistent neurological impairments that significantly affect activities of daily living. Hand functions are essential for doing daily living and working activities. Mirror therapy is shown to be effective in improving hand functional recovery in stroke patients.

Objective: This study aimed to determine the effect of mirror therapy on improving hand functions in Egyptian chronic stroke patients.

Subjects and methods: Thirty chronic ischemic stroke patients from both sexes participated in the study. Their ages ranged from 45 to 65 years. They were randomly assigned into two equal groups: the study group that received a selected physical therapy program in addition to the mirror therapy and the control group that received the same selected physical therapy program but without a mirror therapy. Treatment sessions were conducted three times per week for 8 weeks. Range of motion (ROM) of the wrist extension and forearm supination, hand grip strength, and the time of Jebson Hand Function Test (JHFT) were measured before and after the treatment program.

Results: There were statistically significant increases in the range of motion of the wrist extension and forearm supination and hand grip strength with a decrease in the time of Jebson Hand Function Test in both groups posttreatment. Post-treatment improvement was more significant in the study group compared to the control group.

Conclusion: Mirror therapy had a positive effect on improving hand motor functional skills in a sample of Egyptian chronic stroke patients.
\end{abstract}

Keywords: Hand function, Stroke, Mirror therapy

\section{Introduction}

Upper limb paresis is one of the most common and disabling consequences of stroke that significantly limits activity. It has been stated that $85 \%$ of stroke patients complain of hemiparesis and that 55 to $75 \%$ of them continue to have deficits in the upper extremity activities [1]. Approximately 30-66\% of stroke patients never recover hand motor functional skills, which seriously impacts their performance of the activities of daily life [2].

Numerous rehabilitation techniques for stroke patients have been used to improve hand motor functional skills. These techniques include exercise training for the arm

\footnotetext{
* Correspondence: shaheen.shaimaa@yahoo.com

${ }^{2}$ Neurology Department, Faculty of medicine, Cairo University, Giza, Egypt Full list of author information is available at the end of the article
}

paresis [3], impairment-oriented training of the arm or Bobath therapy for severe arm paresis after stroke, functional electrical stimulation [4], robot-assisted rehabilitation [5], and bilateral arm training [6] constraintinduced movement therapy $[7,8]$. However, most of those rehabilitation techniques for the upper extremity paresis are intensive, involve high equipment costs, and require therapist's manual interaction for a long time, which makes the administration of those treatments difficult for all patients [9].

Mirror therapy (MT) is a cheap, easy, and, most importantly, patient-directed treatment that may improve the recovery of hand motor functional skills [10-13]. MT consists of repeated bilateral, symmetrical movements in which the patient moves the affected body part as much as he/she could while observing the reflection 
of the same unaffected body part in a mirror placed in between those body parts while obscuring the affected part [14]. Researches of neural activities stated that MT might stimulate the areas within the somatosensory and premotor cortex and/or the mirror neuron system in the fronto-temporal region and superior temporal gyrus. This cortical stimulation might produce motor output in patients with stroke $[15,16]$.

This study was designed to assess the efficacy of mirror therapy on improving hand motor functions in a sample of Egyptian chronic stroke patients.

\section{Methods}

This is a case-control study conducted on 30 Egyptian chronic stroke patients (19 men and 11 women; age range 45-65 years). Patients were recruited from the outpatient clinic of the Faculty of Physical Therapy, as they were diagnosed as having an ischemic cerebrovascular stroke in the domain of the carotid system. After, they have received individualized examinations to estimate their suitability according to the following inclusion criteria: not less than 6 months after the onset of stroke, mild spasticity (1:1+: Modified Ashworth Scale) on all joints of the paretic upper extremity [17, 18], active range of motion in the wrist extensors and supinators (grade 3 or more according to the manual muscle test) [19], mild or less cognitive impairment (score > 24: Mini-Mental Status Examination) [20], patients able to sit and maintain balance in a sitting position, and no serious visual perception or vision problems (National Institutes of Health Stroke Scale: subtest, the best gaze and visual) [21]; so that the patient can understand and perform hand motor functional movements that practiced and tested during this study (like writing, turning over 3 by 5 -inch cards, picking up small common objects, simulated feeding, stacking checkers, picking up large objects, and picking up large heavy objects).

The following are the exclusion criteria: hand dysfunction due to causes other than ischemic stroke (as musculoskeletal disorder, orthopedic disease, other neurologic or neuromuscular disorders, surgical intervention in the upper limb), seizure, recurrent stroke, fixed contracture in upper limb joints, or severe spasticity of the affected upper limb. Patients with a grade of muscle power 0 or 1 , patients with acute or recurrent stroke, patients with bony blocks, and patients with any surgical interventions in the upper extremities have been excluded from the study. The aim and procedures were explained to all patients, and informed consents were taken prior to participation. Patients were divided into two equal groups. The study group (15 patients) received a selected physical therapy program and MT while the control group (15 patients) received the same program but without MT.
Pre-test and post-test clinical evaluations were conducted by a physical therapist that was blinded to the participant group. The range of motion of the wrist extension and forearm supination, hand grip strength, and hand motor functional skills were measured to evaluate the improvements in flexibility, motor power, hand motor functional skills, and daily activities.

\section{Assessment procedures}

Patients were submitted to the following: measurement of range of motion by the electronic goniometer (protractor; model: PTHT1015, china 2013), which is a tool used to measure the range of motion of wrist extensors and forearm supinator. It consists of two straight arms, one for the starting point and the other slides with the wrist or fingers to measure the amount of distance moved by them. The electronic goniometer is positioned distal to the axis of motion [22].

Measurement of the hand grip strength has been done by handheld dynamometer (jamar, model number: 63785, China 2013), which is used to measure the hand muscles' maximum isometric strength. It is a hydraulic system, and it has a digital dial for reading results and an adjustable handle with five handle positions [23].

Assessment of hand motor functional skills using the Jebson Hand Function Test (health and care, UK) is a used to evaluate the functional capabilities of patients. This test includes seven items: picking up small common objects, card turning, simulated feeding (bean spooning), picking up large light objects, stacking checkers, picking up large heavy objects, and writing a short sentence. The time of performance was recorded for each test [24].

Stopwatch is a handheld time piece used to measure the time elapsed from the time where it is activated to the time of activation. In this study, it has been used to calculate the Jebson Hand Function Test.

All patients in the study group received a selected physical therapy training program for $40 \mathrm{~min} /$ day, 3 days/week, for 8 weeks. Training sessions were conducted by trained physical therapists and started with warming-up exercises for $5 \mathrm{~min}$ as passive ROM and stretching exercises for the wrist and fingers flexors and extensors then simultaneously symmetrical bilateral hand movements training program for $25 \mathrm{~min}$ : a mirror sized $35 \times 35 \mathrm{~cm}$ made of plastic with a mirror coating was placed across the midline (between the affected and unaffected limbs), so that the affected hand was hidden behind the mirror, and the mirror reflects the image of the non-paretic hand as if it were the paretic hand; in this way, the mirror was large enough for patients to see the whole length of their reflected unaffected hand. Patients were required to perform simultaneously symmetrical 
bilateral hand movements while observing the reflection of the non-paretic hand in the mirror with the hope to create a visual imaginary, whereby movement of the non-paretic hand may be perceived as a movement of the paretic hand. During this arrangement, any jewels should be removed and any scars or tattoo; if present, it has been covered in both limbs before the treatment procedure. The symmetrical bilateral hand movements include wrist extension, finger flexion and extension, forearm supination, gross motor, and fine motor activities. At the end of the session, for $10 \mathrm{~min}$, the patients were subjected to muscle reeducation (for wrist extensors through resting their affected limb on a table while it is pronated, and they were asked to extend the wrist as much as possible; forearm supinator through resting their affected limb on a table while flexing the elbow at $90^{\circ}$, they were asked to supinate the forearm, the therapist may help the patient at first to extend the wrist or supinate the forearm then asked the patient to do it without help); strengthen hand grip (the patients were asked to flex the fingers as fist as much as possible, sometimes the patients were asked to flex the thumb only or make opposition movements by thumb and other fingers); functional training activities (based on task-oriented treatment principles; both fine motor tasks as grasp and grip, and gross motor tasks as reaching) were practiced. The patients in the control group received the same exercise program as the active treatment group last with the same sequence and timings but without the use of the mirror, and the patients were free to observe their affected limb during any exercise.

All statistical tests were performed through the statistical package for social studies (SPSS) \{version 19 for windows, Armonk, NY, 2012\}. Paired $t$ test was conducted for comparison of pre- and post-treatment measures of wrist extension ROM, forearm supination ROM, hand grip strength, and JHFT in each group. Unpaired $t$ test was conducted for comparison of pre- and posttreatment measures of wrist extension ROM, forearm supination ROM, hand grip strength, and JHFT between both groups.

\section{Results}

This is a case-control study. Thirty chronic stroke patients participated in this study. The study group included 15 patients ( 5 females and 10 males), while the control group included 15 patients ( 6 females and 9 males).

The mean age, weight, height, and body mass index (BMI) of the study group were $49 \pm 8.56$ years, 79.06 $\pm 4.72 \mathrm{~kg}, 172.6 \pm 3.41 \mathrm{~cm}$, and $26.56 \pm 1.88 \mathrm{~kg} / \mathrm{m}^{2}$, respectively, while the mean values of the control group for the same measures were $48.2 \pm 9.11$ years,
$80.13 \pm 2.77 \mathrm{~kg}, 173.3 \pm 2.89 \mathrm{~cm}$, and $26.76 \pm 1.45 \mathrm{~kg} /$ $\mathrm{m}^{2}$. There was a statistically insignificant difference between both groups regarding mean age, weight, height, BMI, and duration of illness. $p$ value was 0.8 , $0.45,0.64$, and 0.75 for age, weight, height, and BMI, respectively.

There was a statistically insignificant difference between the study and the control groups regarding the duration of illness. The mean value of the duration of illness of the study group was $21.6 \pm 4.57$ months, while that for the control group was $22.33 \pm 5$ months. $p$ value for the duration of illness was 0.67 .

In the study group, there was a highly significant increase in the mean values of wrist extension ROM between the pre- and post-treatment values. The mean difference between the pre- and post-treatment values was $19.47^{\circ}$ (this indicates the improvement of power in wrist extensors by $54.49 \%$ ). A statistically highly significant difference was found between the pre- and posttreatment values of forearm supination ROM in the study group. The mean difference between the pre- and post-treatment values within the study group was -22.6 ; the percent of improvement in the range of motion of forearm supination and power was $46.82 \%$.

In the control group, there was a significant increase in the mean values of wrist extension ROM between the pre- and post-treatment values. The mean difference was $-7.8^{\circ}$ (this indicates the improvement of power in wrist extensors by $21.27 \%$ ). A statistically highly significant difference was found between the pre- and post-treatment values of forearm supination ROM in the control group. The mean difference in forearm supination ROM within the control group was $-9.34^{\circ}$, and the percent of improvement in range of motion of forearm supination and power was $19.51 \%$ (Table 1).

For hand grip strength, there was a highly statistically significant difference between the pre- and posttreatment values in the study group ( $p$ value $=.0001$ ) The mean difference in the study group was -18.33 , and the percent of improvement was $61.65 \%$. For the control group, a high statistically significant difference was found between the pre- and post-treatment values of the hand grip strength. The mean difference in the control group was -4.6 , and the percent of improvement was 15.23\% (Table 1).

In the study group, there was a highly statistically significant decrease in JHFT post-treatment compared with the pre-treatment values. The mean difference in the study group regarding JHFT was $60.07 \mathrm{~s}$ and the percent of improvement was $44.7 \%$. For the control group, a high statistically significant decrease in JHFT was found in the post-treatment compared to the pre-treatment values. The mean difference in the control group 
Table 1 It show comparison of pre and post treatment mean values of different assessment modalities between both groups

\begin{tabular}{llll}
\hline Assessment modalities & $\begin{array}{l}\text { Study group } \\
\text { mean } \pm \text { SD }\end{array}$ & $\begin{array}{l}\text { Control group } \\
\text { mean } \pm \text { SD }\end{array}$ & $p$-value \\
\hline Wrist extension ROM (Pre) & $35.73 \pm 8.36$ & $36.66 \pm 7.87$ & 0.75 \\
Wrist extension ROM (post) & $55.2 \pm 7.79$ & $44.46 \pm 9.1$ & $0.0002^{* * *}$ \\
Forearm supination ROM (pre) & $48.26 \pm 5.04$ & $47.86 \pm 8.97$ & 0.88 \\
Forearm supination ROM (post) & $70.86 \pm 9.18$ & $57.2 \pm 8.4$ & $0.0001^{* * *}$ \\
Hand grip strength (pre) & $29.73 \pm 7.32$ & $30.2 \pm 8.45$ & 0.87 \\
Hand grip strength (post) & $48.06 \pm 7.46$ & $34.8 \pm 7.41$ & $0.0001^{* * *}$ \\
JHFT (pre) in sec & $134.37 \pm 7.85$ & $132.15 \pm 8.07$ & 0.45 \\
JHFT (post) in sec & $74.3 \pm 6.78$ & $94.03 \pm 7.94$ & $0.0001^{* * *}$ \\
\hline
\end{tabular}

ROM Range of motion, JHFT Jebson Hand Function Test, sec seconds, pre pretreatment, post post treatment, SD standard deviation

*** means statistically high significant value

regarding JHFT was $-38.12 \mathrm{~s}$, and the percent of improvement was $28.84 \%$.

There was a statistically insignificant difference between the study and the control groups regarding the pre-treatment values of wrist extension ROM, forearm supination ROM, hand grip strength, and JHFT.

There were highly significant differences between the study and control groups regarding wrist extension ROM, forearm supination ROM, and hand grip strength post-treatment being higher in the study group. There was also a statistically highly significant difference between both groups regarding mean time JHFT posttreatment being shorter in the study group (meaning better hand function in the study group, the shorter the time the more power of hand function) (Table 1).

\section{Discussion}

Less than $20 \%$ of patients who survive from stroke could recover functional use of the paretic hand which has a negative impact on the quality of life [25, 26]. Mirror therapy is being explored to facilitate recovery in stroke patients through cortical reorganization [27].

Our findings suggest that there is a significant increase of active ROM of wrist extension and forearm supination in addition to improvement of hand functions and its strength of the affected side in both groups post-treatment, especially in the study group. These findings were in agreement with previous studies $[10,12,27,28]$.

Improvements in hand motor functional skills that were facilitated by mirror therapy can be explained in view of Franz and Packman [29] who concluded that mirror therapy could improve the movement and performance of both hands, and Bhasin and colleagues, who proposed that mirror therapy is a form of action observation and has the basis of mirror neurons [30].

Moreover, our patients in the study group who viewed the reflected image of their unaffected limb in the mirror as if it were their affected limb, and perform movements while viewing the mirror, came in accordance with Ezendam and colleagues, who found that performing related motion during MT activates the motor imagery area in the brain and this motor imagery changes can induce neuroplasticity essential for functional recovery of patients with stroke [31].

Spasticity not improved by mirror therapy in the present study which comes in accordance with Gi Jeong Yun and colleagues [32], who found that there was a significant improvement in the Fugl-Meyer assessment score in the wrist, hand, and coordination as well as the power of the hand which gets improved by mirror therapy; however, muscle tone showed no significant improvement.

Mirror therapy can be effective in improving hand motor functional skills in stroke patients. This effectiveness may be explained by three different hypotheses. The first one is the presence of mirror neurons; these neurons fire when the patient tries to imitate an observed action or just looking to an action. This mirror neuronal network includes the supplementary motor area, premotor cortex, inferior frontal gyrus, and inferior parietal lobule. Mirror neurons are important in motor learning which helps the activation of the cortico-spinal tract which is an important method in neurorehabilitation [33].

The second theory assumes that MT activates a normally inhibited projection from the unaffected ipsilateral hemisphere in the hemiparetic patient [31]. The third theory postulates that the hemiparetic patient learned to avoid using his paretic limb, so increasing attention of the patient toward his affected limb mediated by mirror therapy (as if it becomes a moving limb by illusory image) may activate motor networks [34].

\section{Conclusion}

In view of the results of this research study, it could be concluded that mirror therapy is effective in improving 
functions of the hand, and it is advisable to consider it in the rehabilitation programs of chronic stroke patients for a better outcome.

\section{Abbreviations}

ROM: Range of motion; JHFT: Jebson Hand Function Test; SPSS: Statistical Package for Social Studies; MT: Mirror therapy

\section{Acknowledgements}

Not applicable.

\section{Authors' contributions}

H. S. share in putting the concept and design for the study. E. M. share in putting the concept and the design for the study. A. A. follows up the selection of patients and putting the program of physiotherapy. S. S. follows up the selection of patients according to the included criteria and helped in drafting the article. All authors have read and approved the manuscript.

\section{Funding}

There was no funding source.

\section{Availability of data and materials}

The datasets generated and/or analyzed during the current study are not publicly available due to the current Cairo University regulations and Egyptian legislation but are available from the corresponding author on reasonable request and after the institutional approval.

\section{Ethics approval and consent to participate}

This study was approved by the research ethical committee in the Faculty of Physical Therapy, Cairo University, on 31 December 2013. The number of approval is PT.REC/012/00319. A written consent was taken from the patients before sharing in the study.

\section{Consent for publication}

Not applicable.

\section{Competing interests}

There is no competing interests.

\section{Author details}

'Physical therapy for neuromuscular disorder and its surgery, Faculty of physical therapy, Cairo University, Giza, Egypt. ${ }^{2}$ Neurology Department, Faculty of medicine, Cairo University, Giza, Egypt.

\section{Received: 24 December 2019 Accepted: 8 September 2020}

\section{Published online: 29 September 2020}

\section{References}

1. Nichols-Larsen DS, Clark PC, Zeringue A, Greenspan A, Blanton S. Factors influencing stroke survivors' quality of life during sub-acute recovery. Stroke. 2005;36(7):1480-4.

2. Kwakkel G, Kollen BJ, Wagenaar RC. Therapy impact on functional recovery in stroke rehabilitation: a critical review of the literature. Physiotherapy. 1999:85:377-91.

3. Kwakkel G, Wagenaar RC, Twisk JW, Lankhorst GJ, Koetsie JC. Intensity of leg and arm training after primary middle-cerebral-artery stroke: a randomized trial. Lancet. 1999;354(9174):191-6.

4. Ring $\mathrm{H}$, Rosenthal N. Controlled study of neuroprosthetic functional electrical stimulation in sub-acute post-stroke rehabilitation. J Rehabil Med. 2005;37(1):32-6.

5. Masiero S, Celia A, Rosati G, Armani M. Robotic-assisted rehabilitation of the upper limb after acute stroke. Arch Phys Med Rehabil. 2007;88(2):142-9.

6. Summers JJ, Kagerer FA, Garry MI, Hiraga CY, Loftus A, Cauraugh JH. Bilateral and unilateral movement training on upper limb function in chronic stroke patients: a TMS study. J Neurol Sci. 2007;252(1):76-82

7. Dromerick AW, Edwards DF, Hahn M. Does the application of constraintinduced movement therapy during acute rehabilitation reduce arm impairment after ischemic stroke? Stroke. 2000;31:2984-8.

8. Wu CY, Lin KC, Chen HC, Chen $\mathrm{H}$, Hong WH. Effects of modified constraintinduced movement therapy on movement kinematics and daily function in patients with stroke: a kinematic study of motor control mechanisms. Neurorehabil Neural Repair. 2007;21:460-6.

9. Prange G, Hermens HJ, Groothuis-Oudshoorn CG, ljzerman M. Systematic review of the effect of robot-aided therapy on recovery of the hemiparetic arm after stroke. J Rehabil Res Dev. 2006;43(2):171-84.

10. Sathian K, Greenspan Al, Wolf SL. Doing it with mirrors: a case study of a novel approach to neurorehabilitation. Neurorehabil Neural Repair. 2000; 14(1):73-6.

11. Stevens JA, Stoykov ME. Using motor imagery in the rehabilitation of hemiparesis. Arch Phys Med Rehabil. 2003;84(7):1090-2.

12. Yavuzer G, Selles R, Sezer N, Sütbeyaz S, Bussmann JB, Köseoğlu F, et al. Mirror therapy improves hand function in subacute stroke: a randomized controlled trial. Arch Phys Med Rehabil. 2008;89(3):393-8.

13. Michielsen ME, Selles RW, van der Geest JN, Eckhardt M, Yavuzer G, Stam HJ, et al. Motor recovery and cortical reorganization after mirror therapy in chronic stroke patients: a phase II randomized controlled trial. Neurorehabil Neural Repair. 2011;25:223-33.

14. Rothgangel AS, Braun SM, Beurskens AJ, Seitz RJ, Wade DT. The clinical aspects of mirror therapy in rehabilitation: a systematic review of the literature. Int J Rehabil Res. 2011;34:1-13.

15. Dennison A, Hirsch MA, Hammond FM. Rehabilitation with a mirror. Arch Phys Med Rehabil. 2009;90:2155.

16. Lamont K, Chin M, Kogan M. Mirror box therapy: seeing is believing. Explore (NY). 2011;7:369-72

17. Bohannon RW, Smith MB. Interrater reliability of a Modified Ashworth Scale of muscle spasticity. Phys Ther. 1987;67:206-7.

18. Gregson JM, Leathley M, Moore AP, Sharma AK, Smith TL, Watkins CL. Reliability of the Tone Assessment Scale and the Modified Ashworth Scale as clinical tools for assessing poststroke spasticity. Arch Phys Med Rehabil. 1999:80(9):1013-6.

19. Daniels and Worthingham's. Muscle testing: in Helen Hislop, Helen J. Hislop, Jacqueline Montgomery editors. Techniques of manual examination. 8th. WB Saunders, Philadelphia, 2007.

20. Folstein MF, Folstein SE, McHugh PR. "Mini-mental state": a practical method for grading the cognitive state of patients for the clinician. J Psychiatr Res. 1975;12:189-98.

21. Kasner SE, Cucchiara BL, McGarvey ML, Luciano JM, Liebeskind DS, Chalela JA. Modified National Institutes of Health Stroke Scale can be estimated from medical records. Stroke. 2003;34(2):568-70.

22. Foltran FA, Silva LC, Sato TO, Coury HJ. Wrist electrogoniometry: are current mathematical correction procedures effective in reducing crosstalk in functional assessment? Braz J Phys Ther. 2013;17(1):32-40.

23. Merlini L, Mazzone ES, Solari A, Morandi L. Reliability of hand-held dynamometry in spinal muscular atrophy. Muscle Nerve. 2002;26(1):64-70.

24. Beebe JA, Lang CE. Relationships and responsiveness of six upper extremity function tests during the first six months of recovery after stroke. J Neurol Phys Ther. 2009;33(2):96-103.

25. Agnihotri AK, Purwar B, Jeebun N, Agnihotri S. Determination of sex by hand dimensions. Int J Forensic Sci. 2006:1(2):1540-2622.

26. Desrosiers J, Bourbonnais D, Corriveau H, Gosselin S, Bravo G. Effectiveness of unilateral and symmetrical bilateral task training for arm during the subacute phase after stroke: a randomized controlled trial. Clin Rehabil. 2005:19(6):581-93.

27. Altschuler EL, Wisdom SB, Stone L, Foster C, Galasko D, Llewellyn DM, et al. Rehabilitation of hemiparesis after stroke with a mirror. Lancet. 1999: 353(9169):2035-6.

28. Kim H, Shim J. Investigation of the effects of mirror therapy on the upper extremity functions of stroke patients using the manual function test. J Phys Ther Sci. 2015;27(1):227-9.

29. Franz EA, Packman T. Fooling the brain into thinking it sees both hands moving enhances bimanual spatial coupling. Exp Brain Res. 2004;157(2): 174-80.

30. Bhasin A, Padma Srivastava MV, Kumaran SS, Bhatia R, Mohanty S. Neural interface of mirror therapy in chronic stroke patients: a functional magnetic resonance imaging study. Neurol India. 2012;60(6):570-6.

31. Ezendam D, Bongers RM, Jannink MJ. Systematic review of the effectiveness of mirror therapy in upper extremity function. Disabil Rehabil. 2009;31(26): 2135-49.

32. Yun GJ, Chun MH, Park JY, Kim BR. The synergic effects of mirror therapy and neuromuscular electrical stimulation for hand function in stroke patients. Front Hum Neurosci. 2011;13:60. 
33. Pomeroy VM, Clark CA, Miller JSG, Baron JC, Markus HS, Tallis RC. The potential for utilizing the mirror neurone system to enhance recovery of the severely affected upper limb early after stroke: a review and hypothesis. Neurorehabil Neural Repair. 2005;19:4-13.

34. Dohle C, Püllen J, Nakaten A, Küst J, Rietz C, Karbe H. Mirror therapy promotes recovery from severe hemiparesis: a randomized controlled trial. Neurorehabil Neural Repair. 2009;23:209-17.

\section{Publisher's Note}

Springer Nature remains neutral with regard to jurisdictional claims in published maps and institutional affiliations.

Submit your manuscript to a SpringerOpen ${ }^{\mathcal{O}}$ journal and benefit from:

- Convenient online submission

Rigorous peer review

- Open access: articles freely available online

- High visibility within the field

- Retaining the copyright to your article

Submit your next manuscript at $\boldsymbol{\wedge}$ springeropen.com 